\title{
Antistatic Properties of Nanofilled Coatings
}

\author{
B. Gornicka ${ }^{a, *}$, M. MAzur ${ }^{b}$, K. Sieradzka ${ }^{b}$, E. Prociow $^{b}$ And M. LAPinski $^{b}$ \\ ${ }^{a}$ Electrotechnical Institute, Wrocław Division of Electrotechnology and Materials Science \\ M. Sklodowskiej-Curie 55/61, 50-369 Wrocław, Poland \\ ${ }^{b}$ Faculty of Microsystems Electronics and Photonics, Wrocław University of Technology \\ Janiszewskiego 11/17, 50-372 Wrocław, Poland
}

\begin{abstract}
The results of antistatic and electrical properties investigations of nanofilled coatings have been presented. Antistatic performance of materials is essential not only due to safety and preventing of dust and dirt attraction but also effects on an electrical field distribution in the high voltage insulating systems. The polymer coating added with silver and silica nanoparticles were examined by charge decay measurements after corona charging. The charge decay times have varied appreciably between the nanofilled coatings while the volume and surface resistivity of the all tested coatings did not demonstrate meaningful differences. The polyester coating dissipated fairly better than polyesterimide because of its structure and permittivity. It was found that the ability of surface to drain charge away is the better for coatings with of silver nanoparticles whereas the coatings modified with nanosilica shows the poor antistatic properties; the times of charge decay were four order longer then that of unmodified coatings. Barrier properties of nanosilica may be adverse for charge decay.
\end{abstract}

PACS numbers: 81.07.Pr, 82.35.Np

\section{Introduction}

Polymer nanocomposites, obtained by the mixing of polymers and nanofillers (i.e. particles with at least one dimension less than 100 nanometers), give the new opportunities for engineering polymer-based nanocomposites that exhibit advantageous electrical, thermal, mechanical and barrier properties [1-8]. In this paper the results of investigation of some electrical properties of polyester and polyesterimide coatings doped with low quantity nanoparticles are presented. The problem is how adding of metal and non-metal nanoparticles influences antistatic properties of coatings. Antistatic performance testing is not required for these kind of electroinsulating coatings but it can be essential not only due to safety and preventing of dust and dirt attraction but also can affect an electrical field distribution in the high voltage insulating systems.

The suitability of materials to avoid problems caused by static electricity has traditionally been assessed by resistivity value. Several works have shown that there was no relationship between surface resistivity and the ability to dissipate static charge [9]. Studies have shown that corona discharge gives similar results as a tribocharging and charge decay measurements after corona charging can be used for assessment of antistatic properties.

\section{Experimental 2.1. Samples}

Nanofilled coatings were prepared on the basis of two kinds of polymer, polyester (PK) and standard polyester-

\footnotetext{
* corresponding author; e-mail: gornicka@iel.wroc.pl
}

imide $(\mathrm{T})$ and two kinds of nanoadditives, silver and silica nanoparticles. The nanosilver particles have a size below $100 \mathrm{~nm}$ and nanosilica of about $10 \mathrm{~nm}$. The quantity of nanosilver and nanosilica incorporated into coating was $1.3 \%$ and $1.5 \%$ by weight, respectively. The special developed method of disspersing have been used to obtain the nanocomposites. The autors intend to patent that method in the near future. Two kinds of test nanofilled samples have been prepared: for resistance testing in a form of the steel sheets with polymer coatings, and for testing antistatic properties in a form of the cast pieces.

\subsection{Measurements}

Antistatic properties and electrical resistivity of the polymer coatings modified with nanoadditives have been investigated by charge decay measurements after corona charging, using JCI 155 apparatus produced by John Chubb Instrumentation. The main idea of self-dissipation of static electricity on materials is creating a patch of charge on the surface and measuring how quickly the created charge decays. The used method of antistatic measurements is unique and allows measuring the ability of dissipation static charge from the surface. Schematic view of measurement apparatus is shown in Fig. 1.

The JCI 155v5 Charge Decay Test Unit measures the surface voltage and it is mounted on JCI 176 Charge Measuring Sample Support where the sample is put during the measurements. Atmospheric conditions such as temperature and humidity can be controlled with JCI 191 Controlled Humidity Test Chamber. The corona discharge points are mounted on the moving plate, under the fast response fieldmeter. Fieldmeter measures the surface voltage when the plate moves away after corona discharge. A proprietary fast response field mill electro- 


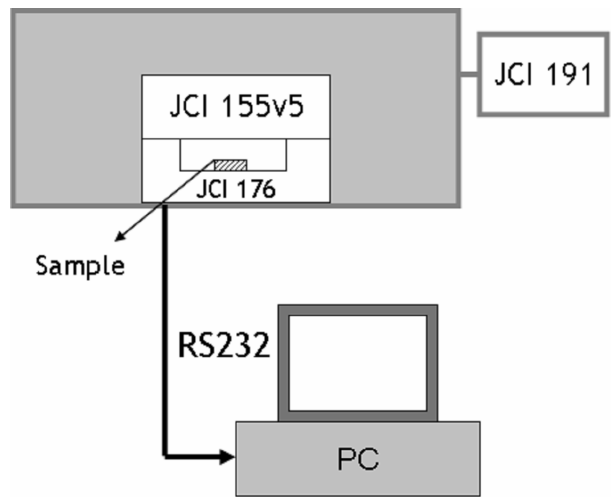

Fig. 1. Schematic view of measurement apparatus.

static fieldmeter gives fast, sensitive and stable measurements of surface potential. The response time is below $10 \mathrm{~ms}$ and charge decay times can be measured from below $50 \mathrm{~ms}$ to many days.

Measurement of surface voltage should start as soon as possible, so plate needs to be moved out quickly of the way after charge deposition. The equipment for charge deposition moves fully away from the region of fieldmeter observation in less than $20 \mathrm{~ms}$. Cluster of corona discharge points provides corona charging in the voltage range from $2 \mathrm{kV}$ to $10 \mathrm{kV}$ and corona time from $10 \mathrm{~ms}$ to $2 \mathrm{~s}$. In this paper samples were charged using positive and negative corona voltage of $5 \mathrm{kV}$ for $20 \mathrm{~ms}$. The software provided opportunity to measure average initial voltage developed by the charge deposited and to record of the charge decay curves [10]. After calibration the error of measurements is below $5 \%$. There were two criteria to assess the ability of material to dissipate static charge from its surface:

- criterion $1 / e$ - decay time measured to $1 / e$ (about $37 \%$ ) of initial peak voltage (Fig. 2);

- criterion $10 \%$ - decay time measured to $10 \%$ of initial peak voltage (Fig. 2).

A simple acceptance test criterion is that the decay time should be:

- less than half a second in the $1 / e$ criterion (initial peak voltage to about $37 \%$ );

- less than $2 \mathrm{~s}$ in the $10 \%$ criterion (initial peak voltage to $10 \%$ ).

Additionally for pure and nanofilled coatings the electrical resistivity under DC test voltage was determined according to IEC 60093 at ambient temperature. The investigation was also performed at elevated temperature, close to the expected thermal endurance of the test coatings $\left(180^{\circ} \mathrm{C}\right)$. The volume and surface resistivity was measured after 1 min using the three electrode arrangements. Applied test voltage was $100 \mathrm{~V}$ and measurements were made after one minute's electrification.

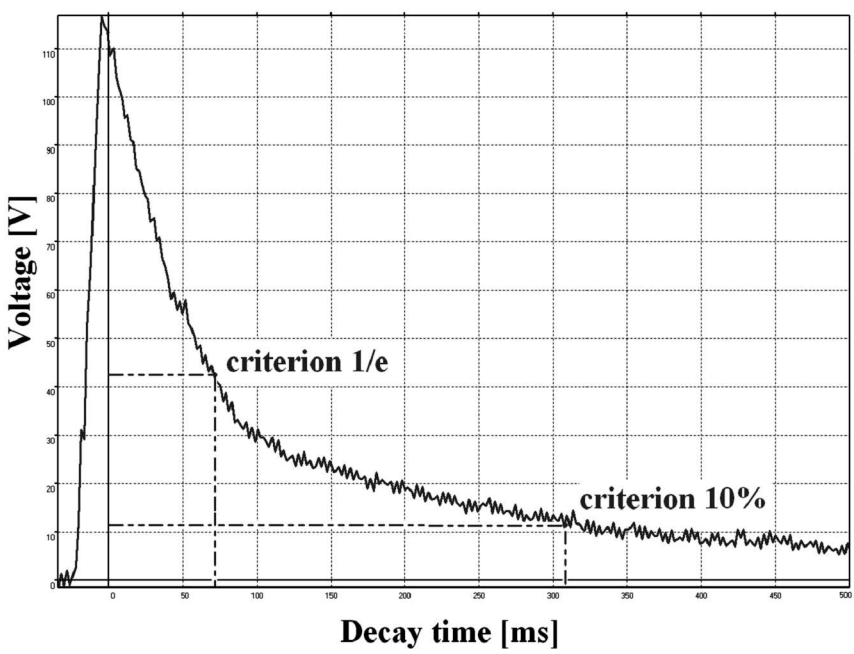

Fig. 2. Example of charge decay time results for positive polarity with marked criteria $1 / e$ and $10 \%$.

\section{Test results}

\subsection{Antistatic properties}

Figures 3 and 4 present the characteristics of decay of surface voltage vs. time for the pure and modified with nanosilver and nanosilica PK coating after the negative and positive polarisation, respectively. The charge decay times have varied appreciably between the nanofilled coatings. The ability of the surface to drain the charge away is the better for coatings with silver nanoparticles, whereas the coatings modified with nanosilica shows the poor antistatic properties. Two kind of polymer samples, polyester PK and polyesterimide $\mathrm{T}$ with and without nanosilica are compared in Fig. 5. It can be noted that the polyester dissipated fairly better than polyesterimide, probably because of the lower nominal electric permittivity and the chemical structure (unsaturated aromatic polyester, without imide bond). Deep traps on the polyesterimide surface are supposed to cause difficulty in charge moving either into the bulk or along the surface [11].

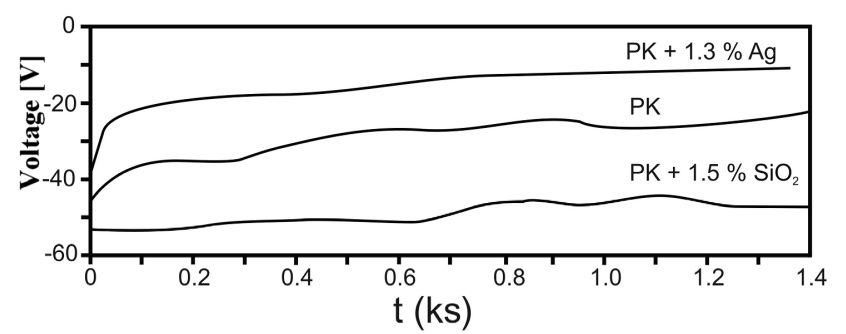

Fig. 3. Decay of surface voltage vs. time for the PK coating: pure (middle curve) and modified with nanosilver (upper curve) and nanosilica (lower curve), corona voltage $5 \mathrm{kV}$, negative polarisation. 


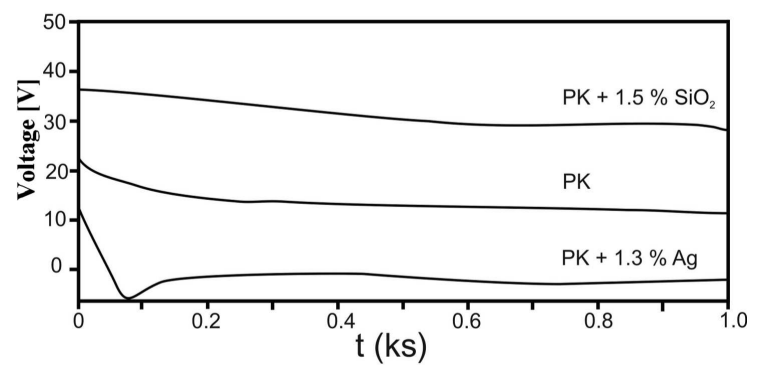

Fig. 4. Decay of surface voltage vs. time for the PK coating: pure (middle curve) and modified with nanosilica (upper curve) and nanosilica (lower curve), corona voltage $5 \mathrm{kV}$, positive polarisation.

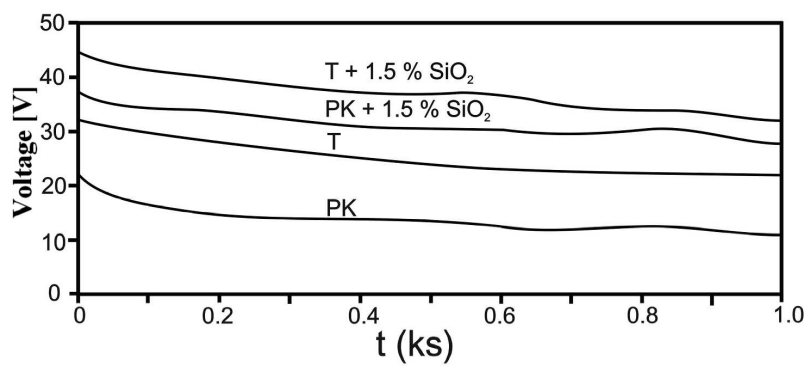

Fig. 5. Decay of surface voltage vs. time for the PK and $\mathrm{T}$ coating: pure and modified with nanosilver and nanosilica, corona voltage $5 \mathrm{kV}$, positive polarisation.

It was found that the ability of surface to drain charge away is the better for coatings with $1.3 \%$ of silver nanoparticles (esspecially for criterion 10\%) whereas the coatings modified with nanosilica show the poor antistatic properties; the times of charge decay were about four order longer then that of unmodified coatings (Table I). There is probably significant influence of barrier effects in the polymer-nanoparticle interface. Although the barrier properties of nanosilica are advantageous for e.g. a decreasing of water absorption and enhancement of resistance to partial discharges of coating but also may be adverse for a charge decay. Total quantity of charge transferred to the sample by the negative corona discharge was considerably greater then by positive one and it can be the reason that values of decay times are much longer for negative corona (Table I). The reason of that can be a fact that in a negative corona total number of electrons may be much higher though the number of very high energy electrons may be lower when compared to a positive corona.

\subsection{Electrical resistivity}

The volume and surface resistivity of polyester coating PK with and without nanosilver are presented in Table II. At ambient temperature both the volume and surface resistivity increases by about one order after adding of a small quantity of nanosilver and some decreases at $180^{\circ} \mathrm{C}$ in compare to the pure coating.

\section{TABLE I}

Values of decay time constants measured (the time from peak voltage to $1 / e$ and $10 \%$ of this value) for polyester $(\mathrm{PK})$ and polyesterimide $(\mathrm{T})$ coating pure and modified with nanosilver and nanosilica.

\begin{tabular}{c|c|c|c|c}
\hline \hline \multirow{2}{*}{$\begin{array}{c}\text { Kind of } \\
\text { coating }\end{array}$} & \multicolumn{2}{|c|}{$\begin{array}{c}\text { Negative } \\
\text { polarisation }\end{array}$} & \multicolumn{2}{c}{$\begin{array}{c}\text { Positive } \\
\text { polarisation }\end{array}$} \\
\cline { 2 - 5 } & $1 / e[\mathrm{~s}]$ & $10 \%[\mathrm{~s}]$ & $1 / e[\mathrm{~s}]$ & $10 \%[\mathrm{~s}]$ \\
\hline $\mathrm{PK}$ with $1.3 \% \mathrm{Ag}$ & 2.64 & 1354 & 0.13 & 20.46 \\
$\mathrm{PK}$ & 1.19 & $>2000$ & 0.18 & $>1000$ \\
$\mathrm{PK}$ with $1.5 \% \mathrm{SiO}_{2}$ & 769.1 & $>2000$ & 415.6 & $>1000$ \\
$\mathrm{~T}$ & 2724 & $>3000$ & 221.8 & $>1000$ \\
$\mathrm{~T}$ with $1.5 \% \mathrm{SiO}_{2}$ & $>5000$ & $>5000$ & 949.1 & $>1000$
\end{tabular}

TABLE II

The volume and surface resistivity of polyester coating PK with and without nanosilver at $23^{\circ} \mathrm{C}$ and $180^{\circ} \mathrm{C}$.

\begin{tabular}{c|c|c|c|c}
\hline \hline & \multicolumn{2}{|c|}{$\begin{array}{c}\text { Volume resistivity } \\
{[\Omega \mathrm{m}]}\end{array}$} & \multicolumn{2}{c}{$\begin{array}{c}\text { Surface resistivity } \\
{[\Omega]}\end{array}$} \\
\cline { 2 - 5 } & $23^{\circ} \mathrm{C}$ & $180{ }^{\circ} \mathrm{C}$ & $23^{\circ} \mathrm{C}$ & $180^{\circ} \mathrm{C}$ \\
\hline $\mathrm{PK}$ & $5.6 \times 10^{13}$ & $4.2 \times 10^{11}$ & $5.5 \times 10^{14}$ & $4.6 \times 10^{13}$ \\
$\mathrm{PK}+1.3 \% \mathrm{Ag}$ & $8.7 \times 10^{14}$ & $3.8 \times 10^{11}$ & $4.1 \times 10^{15}$ & $8.2 \times 10^{12}$
\end{tabular}

At present the mechanism of electric conduction affected by nanoadditives is still difficult to explain. Naturally a very small quantity of nanosilver $(1.3 \%$ by weight at high specific gravity of silver) does not enable achieving the electrical percolation threshold. Other researches also state growth of resistivity at ambient temperature after adding of metal nanoparticles They have found that the capacitor network, which is formed by nanosilver particles in polymer, has evident Coulomb blockade effect, and the conductance is obvious restricted in the composite $[12]$.

\section{Conclusion}

Investigation of antistatic properties of nanofilled coatings shows, that incorporation of a very small amount of silver nanoparticles to polymer coating can improve the ability of surface to drain charge away whereas the adding of nanosilica significantly deteriorates the antistatic properties of coating.

It was also found that at room temperature the volume and surface resistivity of polymer containing $1.3 \mathrm{wt} . \%$ of nanosilver increases compared to the neat polymer probably due to Coulomb blockade effect. Our investigations have shown that there was no relationship between the surface resistivity of the samples and the ability to dissipate static charge. 


\section{Acknowledgments}

This work was financed from the sources granted by NCBiR in the years 2008-2010 as a development research project number N R02 001904 .

\section{References}

[1] M. Kozako, S. Yamano, R. Kido, Y. Ohki, M. Kohtoh, S. Okabe, T. Tanaka, in: Proc. of International Symposium on Electrical Insulating Materials, Vo. 1, 2005 p. 231.

[2] T. Tanaka, IEEE Transaction on Dielectrics and Electrical Insulation, Vol. 12, 2005, p. 914.

[3] C. Zou, J.C. Fothergill, M. Fu, J.K. Nelson, Improving the Dielectric Properties of Polymers by Incorporating Nano-particles, https://lra.le.ac.uk/ bitstream/2381/4068/1/paper11.pdf 2006 .

[4] Y.H. Lai, M.C. Kuo, J.C. Huang, M. Chen, Mater. Sci. Eng. A 458, 158 (2007).
[5] H. Li, G. Liu, B. Liu, W. Chen, S. Chen, Mater. Let. 61, 1507 (2007).

[6] L. Cheng, L. Zheng, G. Li, J. Zeng, Q. Yin, Physica B 4032584 (2008).

[7] S. Pavlidou, C.D. Papaspyrides, Prog. Pol. Sci 33, 1119 (2008).

[8] O. Aso, J.I. Eguiaza'bal, J. Naza'bal, Composites Science and Technology 67, 2854 (2007).

[9] J.N. Chubb, Int. Electrostatics Conf. IoP Conf. Series 143, 1031995.

[10] J.N. Chubb, J. Electrost. 65, 607 (2007).

[11] Y. Hayase, Y. Tanaka, T. Takada, Y. Murata, Y. Sekiguchi, C.C. Reddy, Journal of Physics: Conference Series 183, 1 (2009).

[12] Xu Man, Feng Jun-qiang and Cao Xiao-long, Proceedings of International Symposium on Electrical Insulating p. 83 (2008). 